\title{
Does integration play a role? Academic self-concepts, self-esteem, and self-perceptions of social integration of elementary school children in inclusive and mainstream classes
}

\section{Annette Lohbeck ${ }^{1}$ (D)}

Received: 9 July 2019 / Accepted: 18 August 2020 / Published online: 10 September 2020 (c) The Author(s) 2020

\begin{abstract}
The concept of inclusion is based on the assumption that integrating students with SEN into regular (mainstream) classes would enhance students' performance due to a more stimulating and demanding environment. However, research investigating the effects of inclusive education on students' academic self-concepts has been scarce. For this reason, the present study aimed to examine the specific relationships and differences for math and verbal self-concepts, self-esteem, and self-perceptions of social integration using two samples of elementary school students from grades 2-4: One group of students attended inclusive classes $(n=178)$, whilst the other group attended mainstream classes $(n=188)$. In addition, measurement invariance across classroom setting and possible mediator effects of self-esteem were tested. Results provided support for strong invariance across classroom setting. All constructs were positively correlated with each other. In both math and verbal domains, self-esteem and self-perceptions of social integration proved to be significant predictors of academic self-concepts. Self-esteem was more highly pronounced in younger children, while there were no effects of classroom setting on academic self-concepts. Selfesteem became a significant mediator of the relationships between self-perceptions of social integration and academic self-concepts. No group differences in math and verbal self-concepts, self-esteem, and self-perceptions of social integration were evident.
\end{abstract}

Keywords Academic self-concepts $\cdot$ Self-esteem $\cdot$ Social integration $\cdot$ Classroom setting

Annette Lohbeck

annette.lohbeck@uni-paderborn.de

1 Department of Educational Sciences, University of Paderborn, Warburger Str. 100,

33098 Paderborn, Germany 


\section{Introduction}

The UNESCO (2009) proposed that the inclusion of children into 'regular' (mainstream) schools is the most effective means of combating discriminatory attitudes. The basic assumption of the concept of inclusion is that integrating students with special educational needs (SEN) into mainstream classes would enhance students' performance due to a more stimulating and demanding environment (Gorges et al. 2018). However, the question of whether inclusive education affects students' academic self-concepts has scarcely been examined so far. Little is, in particular, known about the relationships of academic self-concepts with self-esteem and selfperceptions of social integration or differences in these constructs between students attending different classroom settings. The present study aims to address these shortcomings by focusing on two independent samples of elementary school children: One sample attended inclusive classes, whilst the other sample attended mainstream classes. More specifically, the central objective of this study is to reveal (1) the relationships between academic self-concepts, self-esteem, and self-perceptions of social integration as well as (2) differences in these constructs between students attending inclusive and mainstream classes. As academic self-concepts begin to quickly decline until the end of compulsory education (Jacobs et al. 2002), research on the relationships of academic self-concepts with these constructs is of considerable importance and provides important implications for self-concept interventions that are appropriate for students attending different classroom settings.

\subsection{Definitions}

Academic self-concepts are multidimensional constructs that include all self-perceptions of abilities in academic domains (Shavelson et al. 1976). A substantial body of research has cross-culturally supported the multidimensionality and domain-specificity of academic self-concepts (e.g., Arens and Morin 2016; Ehm et al. 2014). In particular, a positive academic self-concept has been found to be related to motivation and better academic achievement (Gogol et al. 2017; Seaton et al. 2014). In contrast, self-esteem is defined as a more global construct of a person's self-evaluation including feelings of self-worth (Rosenberg 1965). Numerous studies have highlighted the beneficial role of self-esteem for various (educational) outcomes such as more functional attribution styles (Rueger and George 2017), higher aspirations (Fang 2016), better academic achievement (Topçu and Leana-Taşcilar 2018), stronger peer attachment (Gorrese and Ruggieri 2013), and higher academic selfconcepts (Arens and Hasselhorn 2014).

Another important factor in the context of inclusive education is students' social integration (Bossaert et al. 2011) that involves interactions and relationships with peers and social acceptance (Szumski and Karwowski 2015). However, although the terms 'social integration', 'social inclusion' and 'social participation' have often been used as synonyms in the literature, the following four themes of social participation/integration can be discerned (see for a review Koster et al. 2009): (1) the presence of positive social contact/interactions between classmates, (2) the acceptance 
of children with SEN by classmates, (3) social relationships/friendships, and (4) students with SEN' perception of acceptance by classmates. The present study focuses on students' self-perceptions of social integration that describe students' evaluation of social integration and acceptance by teachers and classmates. Several studies have shown that higher levels of social integration increased students' well-being (e.g., Kong et al. 2015; Rubin et al. 2016) and academic self-concepts (e.g. Curtin et al. 2013; Shany et al. 2012).

Given these desirable effects of self-esteem and social integration on academic self-concepts, it is worthwhile to examine these effects more specifically to facilitate the design of effective interventions for self-concept enhancement at the early start of education.

\subsection{Review of research}

Research on the interplay of students' academic self-concepts, self-esteem, and self-perceptions of social integration has been scarce. Most studies have focused on group differences between students with and without SEN (e.g., Petry 2018, Schwab 2015; see for a special issue Schwab et al. 2018). For instance, using a sample of 457 students in upper primary regular classes, Avramidis et al. (2018) showed that students with SEN were less socially accepted, had fewer friends, and less social interactions than students without SEN, even if most students with SEN formed one or two mutual friendships which made them feel positive about themselves. In addition, students with SEN have been found to be more vulnerable to lower academic self-concepts than students without SEN due to their academic failure, the stigmatizing nature of their learning problems, and the segregation from mainstream schooling (e.g., Armstrong et al. 2011; Lyons and Arthur-Kelly 2014). For instance, using three studies with ten-year-old students with and without intellectual disability in Poland, Szumski and Karwowski (2015) provided evidence for the big-fish-little-pond effect (BFLPE; Marsh 1987), i.e., the negative influence of class-average achievement on students' academic self-concepts, as students compare their achievement with that of other classmates. In all three studies, the BFLPE was supported: Academic self-concepts were positively related to academic achievement but negatively related to class-average achievement. Furthermore, in study 2 with 5276 students and study 3 with 605 students attending segregated (special) or nonsegregated (integrative and regular) schools, the BFLPE was stronger in students who were highly emotionally integrated into their school but weakly socially integrated with their peers. This research suggests that academic self-concepts of students with SEN are also vulnerable to social comparison effects leading to lower academic self-concepts.

A series of studies has indicated significant relationships between social integration and academic self-concepts of students with SEN (see the meta-analysis by Bear, Minke, and Manning 2002). For instance, drawing on a sample of 498 seventh-grade students with 37 students with SEN, Pijl and Frostad (2010) reported that students with SEN who were not accepted by their peers in regular classes had a lower academic self-concept than their peers without SEN. However, there is 
also evidence (e.g., Avramidis 2013; Krull et al. 2018) that students with SEN held positive academic self-concepts and felt socially accepted by their peers in class. In addition, Gorges et al. (2018) examined the reciprocal effects between academic self-concepts and performance with 446 elementary students with SEN in learning (SEN-L) who received special educational support in exclusive or inclusive settings. In exclusive settings, only students with SEN-L were included, while in inclusive settings, both students with SEN-L and without SEN-L were integrated. Results showed that performance in grade 3 influenced academic self-concept in early grade 4 that, in turn, influenced performance at the end of grade 4 . These cross-lagged effects were clearly evident in both school settings, in particular, in exclusive settings. Accordingly, performance growth also significantly influenced academic selfconcept in both groups of students and was predominantly apparent in exclusive settings. These findings imply that the placement of students with SEN in inclusive schools influences students' academic self-concepts.

Finally, some evidence suggests that student's self-esteem mediates the effects of students' social relationships on various educational outcomes (e.g., Fang 2016; Lau et al. 2018; Li et al. 2018). For instance, using a sample of 262 university students (mean age 19.25 years) in China, Li et al. (2018) found that the relationships of social support with academic achievement and emotional exhaustion were completely mediated through students' self-esteem. Similarly, Fang (2016) showed in a sample of 2491 migrant students from 15 elementary and middle schools in China that students' educational aspirations were positively influenced by social support from family and school as well as by students' self-esteem and socioeconomic status. Furthermore, students' self-esteem mediated the relationships of school and family support with students' educational aspirations. According to these studies, for the present study, it can be assumed that students' self-esteem also mediates the relationships of students' self-perceptions of social integration and academic self-concepts.

In sum, previous research on the interplay between students' academic self-concepts, self-esteem, and social integration as well as differences in these constructs between students attending different classroom settings is rather inconsistent indicating that the integration of students with SEN can either lead to lower or higher academic self-concepts.

\subsection{Aims and hypotheses}

Given the absence and/or scarcity of research on the interplay between students' academic self-concepts, self-esteem, and social integration, the central objective of this study is to reveal the specific relationships between elementary school children's academic self-concepts, self-esteem, and self-perceptions of social integration. The incremental contribution of this study, is, in particular, that two independent samples of elementary school students either attending inclusive schools or integrated into mainstream schools are examined simultaneously. Furthermore, to add to previous research (e.g., Fang 2016; Li et al. 2018; Lau et al. 2018), this study aims to explore potential mediator effects of self-esteem on the relationships between 
self-perceptions of social integration and academic self-concepts as well as latent mean differences in these constructs between students attending inclusive and mainstream classes. Finally, as an aside to the central objectives, the factor structure of all three constructs and measurement invariance across classroom setting are also tested.

Based upon the literature reviewed, the following three hypotheses are addressed:

- Hypothesis 1: Academic self-concepts will be positively related to a higher selfesteem and more positive self-perceptions of social integration.

- Hypothesis 2: A higher self-esteem will be positively related to more positive self-perceptions of social integration.

- Hypothesis 3: Self-esteem will mediate the effects of self-perceptions of social integration on academic self-concepts.

However, due to inconsistency of research, no specific hypotheses for potential differences in academic self-concepts, self-esteem, and self-perceptions of social integration between students attending inclusive and mainstream classes are proposed in this study.

\section{Method}

\subsection{Participants}

The sample consisted of 366 elementary school children aged 7-11 years from five schools. Students were recruited in 26 classes from grades 2-4 (grade 2: $n=135$, grade 3: $n=127$, grade 4: $n=104$ ). Of these, 188 students attended inclusive classes, whilst 178 students attended mainstream classes. In both classroom settings, the proportion of boys and girls was equal (inclusive classes: both girls and boys: $n=94$; mainstream classes: 87 boys, 89 girls). Mean age of the students attending inclusive classes was 8.10 years $(S D=0.93)$, while mean age of the students attending mainstream classes was 8.77 years $(S D=1.07)$. Data collection took place during October 2015 and February 2015.

\subsection{Measures}

\subsubsection{Academic self-concepts}

Children's academic self-concepts in math and German were measured with the short German version of the Self-Description Questionnaire I-GS (SDQ I-GS; Arens et al. 2013). For each domain, three positively formulated items were used (e.g., "I am good at math/German."). To simplify the response format suitable for younger children, the original 5-point response categories format was changed to a 4-point response scale ranging from 1 (false) to 4 (true). Both scales showed high 
reliability estimates (math self-concept: $\alpha=.87, \omega=.92$; German self-concept: $\alpha=.88, \omega=.93)$.

\subsubsection{Self-esteem}

Students' self-esteem was measured with the Rosenberg Self-esteem Scale (RSES) developed by Rosenberg (1979). Due to the young sample, the scale used in the present study was slightly modified, that is, five items (e.g., "On the whole, I am satisfied with myself."), followed by a 4-point response scale ranging from 1 (false) to 4 (true). Internal consistency of this scale was $\operatorname{good}(\alpha=.81, \omega=.89)$.

\subsubsection{Social integration}

Social integration was assessed with a scale of the Academic Integration Questionnaire (AIQ; Haeberlin et al. 1989). The scale used in this study included nine items (e.g., "I have many friends in my class."; "My classmates help me if I need it."), followed by a 4-point response scale ranging from 1 (false) to 4 (true). The internal consistency of this scale was satisfactory $(\alpha=.72, \omega=.81)$.

\subsection{Procedure}

In all schools, a student assistant supervised the administration of the questionnaires and read out the questions to the children. This was done with the help of a classroom teacher to account for the possibility that some of the children may have encountered difficulties in reading the questionnaire. The questionnaire administration took place at a time during regular lessons at school. The duration of the administration of the questionnaires for both groups of students was a whole school lesson of 45 minutes. In both samples, students first completed the scales of social integration and then the scales of self-esteem and academic self-concepts. Participation was voluntary and anonymous. All participants were informed about the purpose of the study and could withdraw at any time without justification. Parental consent was obtained prior to the study, and the Ministry of Education in Lower Saxony approved this study. Further approval by the university ethics committee was not required for this study because this study was supervised by the Ministry of Education in Lower Saxony.

\subsection{Data analysis}

Confirmatory factor analysis (CFA) was performed to test the factor structure of children's self-perceptions. Specifically, for academic self-concepts, a 2-factor model differentiating between math and German self-concepts was estimated, while for both self-esteem and self-perceptions of social integration, two 1-factor models with all items loading on the respective factor were tested. Finally, a 4-factor assuming four distinct factors (i.e., math self-concept, German self-concept, self-esteem, self-perceptions of social integration) was estimated. All factors were defined by the 
items of the respective scales and no cross-loadings were permitted. Due to the parallel wording of some of the items of the two self-concept scales, correlated uniqueness between parallel worded items was allowed.

When testing measurement invariance across classroom setting and potential group differences, classroom setting (inclusive vs. mainstream) was integrated as grouping factor into the 4-factor model. The following three models were considered: a) a configural model assuming the same number of factors defined by the same set of items, while the factor loadings and item thresholds were freely estimated across the two groups of students, b) a strong invariance model stating invariance of the factor loadings and item thresholds, as well as c) a strict invariance model predicting invariance of the factor loadings, item thresholds, and item uniqueness. The weak invariance model was not considered anymore because all items were defined as categorial (see Muthén and Muthén 1998-2018). Latent mean comparisons between students attending inclusive and mainstream classes were analyzed within the strict invariance model with mainstream classes as reference category.

When exploring the relationships of the four constructs and possible mediator effects, two structural equation models (SEMs) for both academic self-concepts as dependent variables with self-esteem and self-perceptions of social integration as independent variables were tested separately. Gender, age, and classroom setting were included as control variables. All models were estimated in Mplus 7.3 (Muthén and Muthén 1998-2018) using the weighted least square means and variance adjusted estimator (WLSMV) and the type = complex option to account for the hierarchical data. Missing values were handled using the Full Information Maximum Likelihood estimator. The amount of missing values of all items was negligible ranging from 0 to $6 \%$.

To evaluate the fit of the models, the comparative fit index (CFI), the TuckerLewis index (TLI), and the root mean square error of approximation (RMSEA) with its confidence interval of $90 \%$ were used. CFI and TLI values above .90 were assumed to indicate a good model fit, while RMSEA values below .05 were interpreted as a close model fit, RMSEA values between .05 and .08 as a reasonable model fit, and RMSEA values greater than .10 as a poor model fit (Kline 2005). Significant fluctuations of the fit indices were analyzed with the DIFF-option implemented in Mplus.

\section{Results}

\subsection{Preliminary analysis: factor structure and measurement invariance}

When testing the factor structure of each of the three constructs (i.e., academic self-concepts, self-esteem, self-perceptions of social integration), all models showed a satisfactory fit to the data. The 4-factor model differentiating between four distinct factors also provided good support for a clear distinction between academic self-concepts, self-esteem, and self-perceptions of social integration. All four factors were well defined by moderate to high item loadings ranging from .22 to .94 . However, there was no strong support for measurement invariance across 
classroom setting. While the strong invariance model did not reveal a significantly worse fit to the data than the configural model (Chi square test for difference testing: $\left.\Delta \chi^{2}=55.99, d f=52, p>.05\right)$, the strict invariance model showed a significantly worse fit to the data than the strong invariance model (Chi square test for difference testing: $\left.\Delta \chi^{2}=38.185, d f=20, p<.01\right)$. As the strong invariance model is considered as the minimal requirement for measurement invariance (Marsh 1994) and tests of latent factor mean comparisons (Marsh et al. 2009), latent means of the two groups of students in the four constructs (i.e., math self-concept, German self-concept, self-esteem, self-perceptions of social integration) were also compared. However, results yielded no significant differences in all four constructs between students attending inclusive and mainstream classes (see Table 1).

\subsection{Correlation analysis}

When exploring the relationships between academic self-concepts, self-esteem, and self-perceptions of social integration, latent correlations for both groups of students attending inclusive and mainstream classes were examined separately (see Table 2).

In both groups of students, German self-concepts were significantly positively related to self-esteem and self-perceptions of social integration. However, only math self-concepts of students attending mainstream classes were substantially positively related to both their self-esteem and self-perceptions of social integration, while math self-concepts of students attending inclusive classes were only significantly positively related to their self-esteem. Furthermore, in both groups of students, selfesteem was significantly positively related to self-perceptions of social integration. All correlations were numerically lower in students attending inclusive classes, except for the correlation of German self-concept and self-perceptions of social integration, which was numerically higher in students attending inclusive classes than that of students attending mainstream classes. In both groups of students, both academic self-concepts were not substantially correlated with each other.

Table 1 Goodness of fit indices for the models estimated in this study

\begin{tabular}{lrrrrrl}
\hline Models & \multicolumn{1}{c}{$\chi^{2}$} & $d f$ & CFI & TLI & RMSEA [90\% CI] & $\beta$ \\
\hline 2-factor model of self-concepts & 16.181 & 5 & .996 & .987 & $.078[.038-.123]$ & $.81-.93$ \\
1-factor model of self-esteem & 9.803 & 5 & .994 & .989 & $.051[.000-.099]$ & $.70-.88$ \\
1-factor model of social integration & 80.826 & 27 & .928 & .904 & $.074[.056-.093]$ & $.25-.77$ \\
4-factor model & 251.794 & 164 & .968 & .963 & $.038[.029-.047]$ & $.22-.94$ \\
Measurement invariance & & & & & & \\
$\quad$ Configural & 422.172 & 328 & .961 & .955 & $.040[.027-.050]$ & \\
Strong & 478.162 & 380 & .960 & .960 & $.038[.026-.048]$ & \\
Strict & 516.347 & 400 & .952 & .955 & $.040[.029-.049]$ & \\
\hline
\end{tabular}

$\chi^{2}=$ Chi square, $T L I=$ Tucker-Lewis index, $\mathrm{CFI}=$ comparative fit index, RMSEA = root mean square error of approximation, $\mathrm{CI}=$ confidence interval 


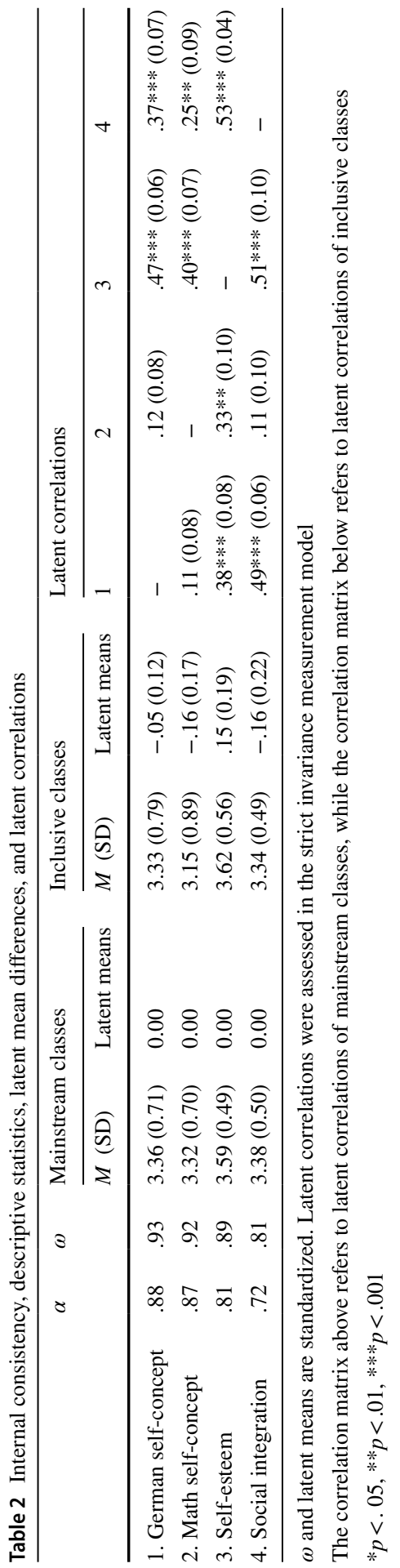




\subsection{Regression analysis}

Similar results were found in the SEM considering academic self-concepts as dependent variables separately, with self-esteem and self-perceptions of social integration as independent variables and gender, age, and classroom setting as control variables (see Table 3).

In Model 1 considering German self-concept as dependent variable, selfesteem and self-perceptions of social integration were significantly positively linked to German self-concept. Self-perceptions of social integration, in turn, were significantly positively linked to self-esteem, which significantly mediated the relationships of self-perceptions of social integration on German self-concepts. The total direct effect was $.44(S E=0.14)$, while the total indirect effect was .13 $(S E=0.05)$. Furthermore, girls showed a significantly higher German self-concept than boys, and younger children reported a significantly higher self-esteem than older children. In contrast, for classroom setting, there was no support for a significant effect. The fit of this model was good $\left(\chi^{2}=199.962\right.$, $d f=161, C F I=.979, T L I=.975, R M S E A=.026$ [.011-.037]), with an explained variance of .30 for German self-concept and .35 for self-esteem.

In Model 2 considering math self-concept as dependent variable, both selfesteem and self-perceptions of social integration were also significantly positively linked to math self-concept. As in Model 1, self-perceptions of social integration were significantly positively linked to self-esteem, which proved to be a significant mediator of the relationships between self-perceptions of social integration and math self-concept. The total direct effect was $.19(S E=0.13)$, while the total indirect effect was $.14(S E=0.09)$. In contrast, gender became a nonsignificant predictor of math self-concept, while there was also evidence that younger children reported a higher self-esteem than older children. The negative regression coefficient of the classroom setting slightly missed the significance level $(p=.050)$ due to its high standard deviation $(S E=.14)$. The fit of the model was satisfactory $\left(\chi^{2}=230.887, d f=161, C F I=.967, T L I=.962, R M S E A=.035\right.$ [.024-.044]), with an explained variance of .14 for math self-concept and .35 for self-esteem (see Fig. 1).

\section{Discussion}

By using two independent samples of elementary school children attending inclusive or mainstream classes, the present study examined 1) the relationships of math and verbal self-concepts, self-esteem, and self-perceptions of social integration, 2) potential mediator effects of self-esteem on the relationships between self-perceptions of social integration and academic self-concepts, as well as 3) latent group differences in these constructs. Furthermore, the factor structure of each of the constructs and measurement invariance across classroom setting were tested. 


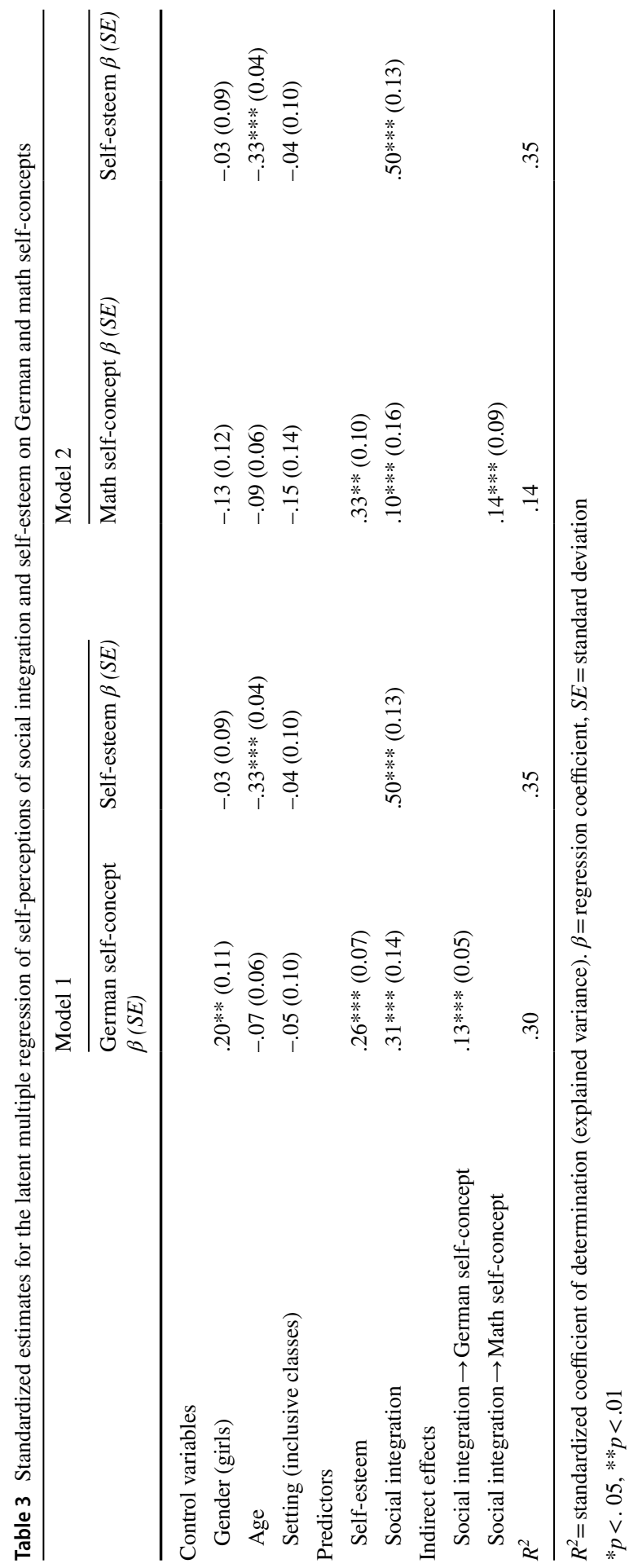



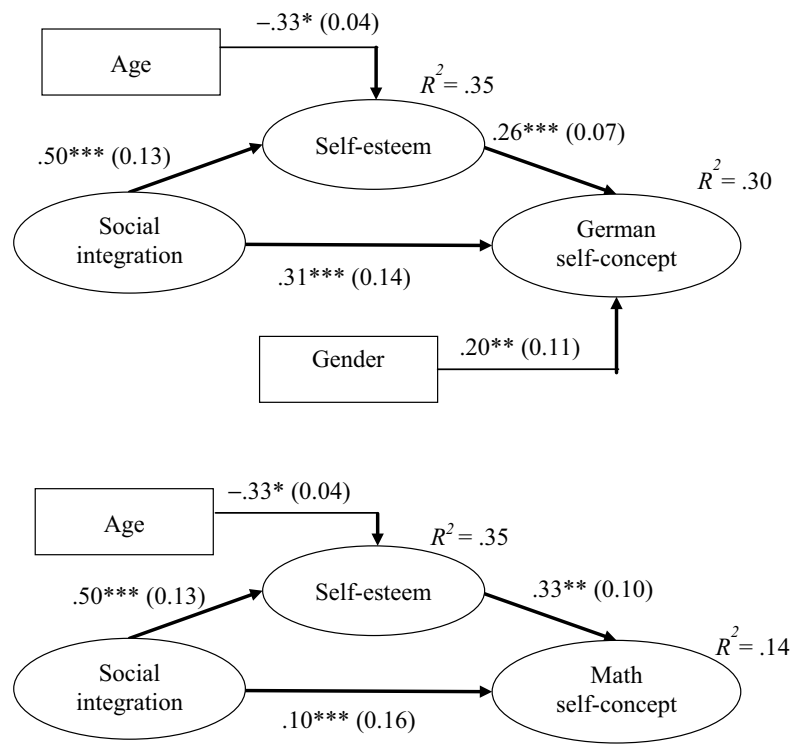

${ }^{*} p<.05,{ }^{* *} p<.01,{ }^{* * *} p<.001$

Fig. 1 Models under investigation

\subsection{Factor structure and measurement invariance}

Results of CFA showed that all constructs were clearly separable from each other. Specifically, there was evidence for a 2-factor model of academic self-concepts differentiating between two domain-specific academic self-concepts. This result is congruent with previous research (e.g., Arens and Morin 2016; Ehm et al. 2014) stating the multidimensionality of academic self-concepts. However, there was no support for strong measurement invariance across classroom setting with the 4-factor model assuming four distinct factors for math self-concept, German self-concept, self-esteem, and self-perceptions of social integration. While the strong invariance model did not reveal a significantly worse fit to the data than the configural model, the strict invariance model yielded a significantly worse fit to the data than the strong invariance model.

\subsection{Latent correlations}

Results of bivariate correlation analysis showed that irrespective of the classroom setting, German self-concepts were significantly positively related to self-esteem and self-perceptions of social integration. However, there was only partial support for Hypothesis 1 because only math self-concepts of students attending mainstream classes were substantially positively related to self-esteem and self-perceptions of 
social integration. In contrast, math self-concepts of students attending inclusive classes were only significantly positively related to self-esteem. A possible reason for the non-significant correlation of math self-concepts with self-perceptions of social integration in students attending inclusive classes may be that math self-concepts of these students are less pronounced than those of students attending mainstream classes, as also indicated by the descriptive statistics of this study.

In support of Hypothesis 2 and previous research (see the meta-analysis by Gorrese and Ruggieri 2013), in both groups of students, self-esteem and self-perceptions of social integration were significantly positively correlated with each other. This finding suggests that students with a higher self-esteem perceive their social integration in class positively, irrespective of the classroom setting.

\subsection{Regression analysis}

Similar results were found in the regression analysis estimated subsequently in this study: In both domains, self-esteem and self-perceptions of social integration were significantly positively linked to academic self-concepts. Self-perceptions of social integration, in turn, became a significantly positive predictor of self-esteem, which was more highly pronounced in younger children. In contrast, in both domains, there were no significant effects of classroom setting on academic self-concepts. However, in the math domain, the negative regression coefficient of classroom setting was numerically high $(\beta=-.15)$, even if not significant $(p=.050)$ due to its high standard deviation $(S E=0.14)$. This result indicates that students attending inclusive classes are more likely to develop a negative math self-concept than students attending mainstream classes. A possible reason for this result is that students make social comparisons, leading to lower academic self-concepts, as evidenced by the BFLPE research (Becker and Neumann 2016; Szumski and Karwowski 2015).

Finally, in both domains, there was support for Hypothesis 3 and earlier studies (e.g., Fang 2016; Li et al. 2018) highlighting that students' self-perceptions of social integration and self-esteem are of considerable importance for their academic selfconcepts: Self-esteem significantly mediated the relationships between self-perceptions of social integration and academic self-concepts.

\subsection{Latent mean comparisons}

No support was found for significant latent mean differences in both academic selfconcepts, self-esteem, and self-perceptions of social integration. Rather, results indicated that irrespective of the classroom setting, both groups of students showed similar academic self-concepts, similar levels of self-esteem, and perceived social integration in a comparable way. These are desirable findings stating that the inclusion of students with SEN in mainstream classes, where there are most of the students without SEN, does not affect children's academic self-concepts, self-esteem, and self-perceptions of social integration. A possible reason for this research finding may be that elementary school children use their peers as social comparison group, whose achievement is relatively similar, so that they perceive their competence 
positively. This assumption is based on Festinger's (1954) social comparison framework positing that individuals are more likely to make comparisons with similar rather than dissimilar others, resulting in more positive self-concepts than comparisons with more able out-groups. If this was the case, the majority of students with SEN should have spontaneously selected their peers with SEN in the resource facility, they attended as their social comparison group. However, given the crosscultural support for the BFLPE, even in younger samples of elementary school children (e.g., Becker and Neumann 2016; Wouters et al. 2013), the negative effects of inclusion on students' academic self-concepts, although not predicted a priori on the basis of BFLPE research, are also reasonable. In particular, research by Szumski and Karwowski (2015) investigating the BFLPE among ten-year-old students with and without intellectual disability provided support for this assumption. This research challenges special education policy makers and practioners to recognize that the inclusion of students in mainstream classes is likely to result in lower academic self-concepts of students with SEN (Pijl and Frostad 2010) due to the commonly higher class-average achievement levels of students in mainstream classes. As a result, appropriate strategies are needed to counter this negative effect of inclusion rather than accepting the largely unsupported inference from labeling theory that the effects of inclusion on academic self-concepts are positive (OECD 2009). In particular, the school environment seems to trigger social comparisons from the early start of education when children experience some form of evaluation with reference to the ability of other children that surround them (Wouters et al. 2013). This is a particularly pertinent issue for children with SEN, as they are a minority group holding lower academic achievement levels amongst a majority group of children without SEN with higher academic achievement levels.

\subsection{Limitations}

Results of the present study need to be interpreted cautiously for several reasons.

A first limitation of this study concerns its cross-sectional design which does not provide solid evidence for causal effects or the direction of effects. In the present study, only the effects of self-perceptions of social integration and self-esteem on academic self-concepts were focused upon, even though also the opposite direction is reasonable. For instance, if a student has a lower academic self-concept, he or she may also have a lower self-esteem and may feel less socially accepted by his or her classmates. Longitudinal studies are therefore needed to provide solid empirical evidence for the causality of the variables. An additional benefit of longitudinal studies, is, in particular, the investigation of the effects of integration on academic self-concepts of students moving from special schools to integrated placements in mainstream schools. For this reason, further research could, for instance, examine just one group of students measuring academic self-concepts whilst initially in special schools and after integration into mainstream schools. This would provide clearer evidence of the effects of integration on academic self-concepts and social comparison group choice. Furthermore, as the present study only considered gender, age, and classroom setting as control variables in the regression, further studies 
should also take other confounding variables into account, such as children's socioeconomic background or relationships with peers and teachers.

\subsection{Implications}

Despite the limitations mentioned, the results of this study provide some important implications for policies of inclusive education that warrant further investigation. In terms of current integration policy, the significantly positive effects of self-esteem and self-perceptions of social integration on both academic self-concepts imply that integration does have positive benefits on elementary school children's academic self-concepts. This aligns with the central aim of integration policy, that is, combating discriminatory attitudes. In addition, the significant mediator effects of self-esteem on the relationships between self-perceptions of social integration and both academic self-concepts highlight the crucial role of self-esteem for elementary school children. School interventions aiming at enhancing children's academic selfconcepts should therefore take children's self-esteem into account. Finally, of great interest in this investigation is also that students attending inclusive and mainstream classes showed similar academic self-concepts, similar levels of self-esteem, and perceived social integration in a comparable way. This finding indicates that social comparison group selection is no significant determinant of students' academic selfconcepts, self-esteem, and perceived social integration. An important implication of this finding is that the integration of students with SEN in mainstream classes has no detrimental effects on students' academic self-concepts, self-esteem, and perceived social integration. Students with SEN can thus be well integrated into mainstream classes, as these students may face no greater levels of stigmatization than those attending mainstream schools, supporting their well-being and development at school.

\subsection{Conclusion}

The present study extended previous research by showing the following results: (a) Academic self-concepts of elementary school children are closely related to their self-esteem and self-perceptions of social integration, irrespective of the classroom setting. (b) Self-esteem mediates the effects of self-perceptions of social integration on academic self-concepts. (c) Students attending inclusive and mainstream classes have quite similar academic self-concepts, (d) show a similar self-esteem, and (e) perceive social integration in a comparable way. This research is of considerable importance given that social integration is particularly salient to students with SEN who are often less accepted by their peers without SEN (Bossaert et al. 2013).

Funding This research did not receive any specific grant from funding agencies in the public, commercial, or not-for-profit sectors. Open Access funding provided by Projekt DEAL. 


\section{Compliance with ethical standards}

Conflict of interest The author declares no conflict of interest.

Open Access This article is licensed under a Creative Commons Attribution 4.0 International License, which permits use, sharing, adaptation, distribution and reproduction in any medium or format, as long as you give appropriate credit to the original author(s) and the source, provide a link to the Creative Commons licence, and indicate if changes were made. The images or other third party material in this article are included in the article's Creative Commons licence, unless indicated otherwise in a credit line to the material. If material is not included in the article's Creative Commons licence and your intended use is not permitted by statutory regulation or exceeds the permitted use, you will need to obtain permission directly from the copyright holder. To view a copy of this licence, visit http://creativecommons.org/licen ses/by/4.0/.

\section{References}

Arens, A. K., \& Hasselhorn, M. (2014). Age and gender differences in the relation between self-concept facets and self-esteem. The Journal of Early Adolescence, 34(6), 760-791. https://doi. org/10.1177/0272431613503216.

Arens, A. K., \& Morin, A. J. S. (2016). Examination of the structure and grade-related differentiation of multidimensional self-concept instruments for children using ESEM. The Journal of Experimental Education, 84(2), 330-355. https://doi.org/10.1080/00220973.2014.999187.

Arens, A. K., Yeung, A. S., Craven, R. G., \& Hasselhorn, M. (2013). A short German version of the self-description questionnaire I: Theoretical and empirical comparability. International Journal of Research \& Method in Education, 36(4), 415-438. https://doi.org/10.1080/1743727X.2012.710503.

Armstrong, D., Armstrong, A. C., \& Spandagou, I. (2011). Inclusion: By choice or by chance? International Journal of Inclusive Education, 15(1), 29-39. https://doi.org/10.1080/13603116.2010.49619 2.

Avramidis, E. (2013). Self-concept, social position and social participation of pupils with SEN in mainstream primary schools. Research Papers in Education, 28(4), 421-442. https://doi. org/10.1080/02671522.2012.673006.

Avramidis, E., Avgeri, G., \& Strogilos, V. (2018). Social participation and friendship quality of students with special educational needs in regular Greek primary schools. European Journal of Special Needs Education, 33(2), 221-234. https://doi.org/10.1080/08856257.2018.1424779.

Bear, G. G., Minke, K. M., \& Manning, M. A. (2002). Self-concept of students with learning disabilities: A meta-analysis. School Psychology Review, 31(3), 405-427.

Becker, M., \& Neumann, M. (2016). Context-related changes in academic self-concept development: On the long-term persistence of big-fish-little-pond effects. Learning and Instruction, 45, 31-39. https ://doi.org/10.1016/j.learninstruc.2016.06.003.

Bossaert, G., Colpin, H., Pijl, S. P., \& Petry, K. (2011). Loneliness among students with special educational needs in mainstream seventh grade. Research in Developmental Disabilities, 33(6), 18881897. https://doi.org/10.1016/j.ridd.2012.05.010.

Bossaert, G., Colpin, H., Pijl, S. J., \& Petry, K. (2013). Truly included? A literature study focusing on the social dimension of inclusion in education. International Journal of Inclusive Education, 17(1), 60-79. https://doi.org/10.1080/13603116.2011.580464.

Curtin, N., Stewart, A. J., \& Ostrove, J. M. (2013). Fostering academic self-concept: Advisor support and sense of belonging among international and domestic graduate students. American Educational Research Journal, 50(1), 108-137. https://doi.org/10.3102/0002831212446662.

Ehm, J.-H., Lindberg, S., \& Hasselhorn, M. (2014). Reading, writing, and math self-concept in elementary school children: Influence of dimensional comparison processes. European Journal of Psychology of Education, 29(2), 277-294. https://doi.org/10.1007/s10212-013-0198-x.

Fang, L. (2016). Educational aspirations of Chinese migrant children: The role of self-esteem contextual and individual influences. Learning and Individual Differences, 50, 195-202. https://doi. org/10.1016/j.lindif.2016.08.009. 
Festinger, L. (1954). A theory of social comparison processes. Human Relations, 7(2), 117-140. https:// doi.org/10.1177/001872675400700202.

Gogol, K., Brunner, M., Martin, R., Preckel, F., \& Goetz, T. (2017). Affect and motivation within and between school subjects: Development and validation of an integrative structural model of academic self-concept, interest, and anxiety. Contemporary Educational Psychology, 49, 46-65. https://doi. org/10.1016/j.cedpsych.2016.11.003.

Gorges, J., Neumann, P., Wild, E., Stranghöner, D., \& Lütje-Klose, B. (2018). Reciprocal effects between self-concept of ability and performance: A longitudinal study of children with learning disabilities in inclusive versus exclusive elementary education. Learning and Individual Differences, 61, 11-20. https://doi.org/10.1016/j.lindif.2017.11.005.

Gorrese, A., \& Ruggieri, R. (2013). Peer attachment and self-esteem: A meta-analytic review. Personality and Individual Differences, 55(5), 559-568. https://doi.org/10.1016/j.paid.2013.04.025.

Haeberlin, U., Bless, G., Moser, U., \& Klaghofer, R. (1989). Integration in die Schulklasse: Fragebogen zur Erfassung von Dimensionen der Integration von Schülern: FDI 4-6 [Integration in the classroom: Questionnaire for assessing dimensions of student integration: FDI 4-6]. Bern: Haupt Verlag.

Jacobs, J. E., Lanza, S., Osgood, D. W., Eccles, J. S., \& Wigfield, A. (2002). Changes in children's selfcompetence and values: Gender and domain differences across grades one through twelve. Child Development, 73(2), 509-527. https://doi.org/10.1111/1467-8624.00421.

Kline, T. J. B. (2005). Psychological testing: A practical approach to design and evaluation. Thousand Oaks: Sage.

Kong, F., Ding, K., \& Zhao, J. (2015). The relationships among gratitude, self-esteem, social support and life satisfaction among undergraduate students. Journal of Happiness Studies, 16(2), 477-489. https ://doi.org/10.1007/s10902-014-9519-2.

Koster, M., Nakken, H., Pijl, S. J., \& van Houten, E. (2009). Being part of the peer group: A literature study focusing on the social dimension of inclusion in education. International Journal of Inclusive Education, 13(2), 117-140. https://doi.org/10.1080/13603110701284680.

Krull, J., Wilbert, J., \& Hennemann, T. (2018). Does social exclusion by classmates lead to behaviour problems and learning difficulties or vice versa? A cross-lagged panel analysis. European Journal of Special Needs Education, 33(2), 235-253. https://doi.org/10.1080/08856257.2018.1424780.

Lau, E. Y. H., Chan, K. K. S., \& Lam, C. B. (2018). Social support and adjustment outcomes of first-year university students in Hong Kong: Self-esteem as a mediator. Journal of College Student Development, 59(1), 129-134. https://doi.org/10.1353/csd.2018.0011.

Li, J., Han, X., Wang, W., Sun, G., \& Cheng, Z. (2018). How social support influences university students' academic achievement and emotional exhaustion: The mediating role of self-esteem. Learning and Individual Differences, 61, 120-126. https://doi.org/10.1016/j.lindif.2017.11.016.

Lyons, G., \& Arthur-Kelly, M. (2014). UNESCO inclusion policy and the education of school students with profound intellectual and multiple disabilities: Where to now? Creative Education, 5(7), 445456. https://doi.org/10.4236/ce.2014.57054.

Marsh, H. W. (1987). The big-fish-little-pond-effect on academic self-concept. Journal of Educational Psychology, 79(3), 280-295. https://doi.org/10.1037/0022-0663.79.3.280.

Marsh, H. W. (1994). Using the national longitudinal study of 1988 to evaluate theoretical models of selfconcept: The self-description questionnaire. Journal of Educational Psychology, 80(3), 439-456. https://doi.org/10.1037/0022-0663.86.3.439.

Marsh, H. W., Muthén, B., Asparouhov, T., Lüdtke, O., Robitzsch, A., Morin, A. J. S., et al. (2009). Exploratory structural equation modeling, integrating CFA and EFA: Application to students' evaluations of university teaching. Structural Equation Modeling: A Multidisciplinary Journal, 16(3), 439-476. https://doi.org/10.1080/10705510903008220.

Muthén, L. K. \& Muthén, B. O. (1998-2018). Mplus user's guide. Los Angeles, CA: Muthén \& Muthén.

Petry, K. (2018). The relationship between class attitudes towards peers with a disability and peer acceptance, friendships and peer interactions of students with a disability in regular secondary schools. European Journal of Special Needs Education, 33(4), 254-268. https://doi.org/10.1080/08856 257.2018.1424782.

Pijl, S. J., \& Frostad, P. (2010). Peer acceptance and self-concept of students with disabilities in regular education. European Journal of Special Needs Education, 25(1), 93-105. https://doi. org/10.1080/08856250903450947.

Rosenberg, M. (1965). Society and the adolescent self-image. Princeton, NJ: Princeton University Press. Rosenberg, M. (1979). Conceiving the self. New York: Basic Books. 
Rubin, M., Evans, O., \& Wilkinson, R. B. (2016). A longitudinal study of the relations among university students' subjective social status, social contact with university friends, and mental health and well-being. Journal of Social and Clinical Psychology, 35(9), 722-737. https://doi.org/10.1521/ jscp.2016.35.9.722.

Rueger, S. Y., \& George, R. (2017). Indirect effects of attributional style for positive events on depressive symptoms through self-esteem during early adolescence. Journal of Youth and Adolescence, 46(4), 701-708. https://doi.org/10.1007/s10964-016-0530-2.

Schwab, S. (2015). Social dimensions of inclusion in education of 4th and 7 th grade pupils in inclusive and regular classes: Outcomes from Austria. Research in Developmental Disabilities, 43-44, 72-79. https://doi.org/10.1016/j.ridd.2015.06.005.

Schwab, S., Nel, M., \& Hellmich, F. (2018). Social participation of students with special educational needs. European Journal of Special Needs Education, 33, 163-165. https://doi.org/10.1080/08856 257.2018.1424784.

Seaton, M., Parker, P., Marsh, H. W., Craven, R. G., \& Yeung, A. S. (2014). The reciprocal relations between self-concept, motivation and achievement: Juxtaposing academic self-concept and achievement goal orientations for mathematics success. Educational Psychology, 34(1), 49-72. https://doi. org/10.1080/01443410.2013.825232.

Shany, M., Wiener, J., \& Assido, M. (2012). Friendship predictors of global self-worth and domain-specific self-concepts in university students with and without learning disability. Journal of Learning Disabilities, 46(5), 444-452. https://doi.org/10.1177/0022219412436977.

Shavelson, R. J., Hubner, J. J., \& Stanton, G. C. (1976). Self-concept: Validation of construct interpretations. Review of Educational Research, 46, 407-441.

Szumski, G., \& Karwowski, M. (2015). Emotional and social integration and the big-fish-little-pond effect among students with and without disabilities. Learning and Individual Differences, 43, 63-74. https://doi.org/10.1016/j.lindif.2015.08.037.

Topçu, S., \& Leana-Taşcılar, M. Z. (2018). The role of motivation and self-esteem in the academic achievement of Turkish gifted students. Gifted Education International, 34(1), 3-18. https://doi. org/10.1177/0261429416646192.

UNESCO. (2009). Policy guidelines on inclusion in education. Paris: UNESCO.

Wouters, S., Colpin, H., Van Damme, J., De Laet, S., \& Verschueren, K. (2013). Early adolescents' academic self-concept formation: Do classmates or friends matter most? Learning and Individual Differences, 27, 193-200. https://doi.org/10.1016/j.lindif.2013.09.002.

Publisher's Note Springer Nature remains neutral with regard to jurisdictional claims in published maps and institutional affiliations.

Annette Lohbeck earned her doctoral degree at the University of Bremen in 2014. Since 2020, she manages the professorship of emotional and social development in inclusive schools at the University of Paderborn. Her research focuses on teachers' and students' self-concepts, motivation, and emotions, explaining possible individual differences in various educational outcomes. 